\title{
IMPROVING THE QUALITY OF DRAWINGS
}

\author{
Pertti Järvinen \\ University of Tampere \\ Finland
}

\begin{abstract}
In scientific communication we often use words and drawings. The most serious wish of the researcher may be that his or her article will communicate. Non-native authors can make errors in using English. With drawings he or she can better succeed in transferring his/her main ideas, because graphs and pictures can comprise a common language.

Although this graphical language seemed to be promising, we found some problems in using it. The problems we found concerned such relationships as partitioning a whole into components, real or imagined correlation between activities, ranking or nesting particular activities in a priority order, and implicitly assumed top-down flow. We picked up some real cases from highly ranked journals and other sources to demonstrate smaller or larger deficiencies in the drawings and how those faults can be fixed. Finally we collect our results as a set of lessons learned.
\end{abstract}

\section{INTRODUCTION}

Drawings, images or graphics are one of mankind's oldest methods of communication and documentation. Our well-developed two- and threedimensionally oriented eye-brain pattern recognition mechanism does indeed allow us to perceive and process many types of data very rapidly and efficiently if the data are presented pictorially (Foley and van Dam 1982). The use of graphics is rapidly increasing. In fact, the ancient Chinese proverb, "a picture is worth a thousand words", could only become a cliché in our society after the introduction of technological means of easily and cheaply producing and reproducing pictures (Salmelin 1997).

Graphs have become a pervasive part of our environment; they appear in magazines, newspapers and journals, on television and on cereal boxes (Kosslyn 1994 p.2). Given their near ubiquity, it is surprising that so few graphs communicate effectively. Many of our examples below confirm that claim, and therefore our purpose in this paper is to find some guidelines how to draw a framework, model or other construct consisting of multiple elements and their relationships. Thus we restrict our consideration on the examples found in research reports, and hence we emphasise conceptual clarity, and not amusement, attraction, etc.

In the literature there are principles on how to present quantitative information in the figured form in general (Tufte 1983, Kosslyn 1994), in 
managerial decision-making (Jarvenpaa and Dickson 1988) and in medical research (Salmelin 1997), but the author did not find any instructions how to draw conceptual models. The idea of theoretical sampling (Strauss and Corbin 1990 p.176) was used to select examples. After analysis of a certain figure we present the lessons learned. They provide the basis to intelligently move forward in this area. In other words, researchers should be able to replicate and accept certain graphical practice as fact (the base), and add to our knowledge of good graphic practice predicated upon a concrete set of practices.

\section{PARTITIONING}

Silver et al. (1995) described their proposal for the MBA core course in information systems. In teaching they wanted to communicate with MBA students by starting with a theory that is close to their audience's initial view of the world. According to their view, the would-be MBA - a future entrepreneur or CEO of an enterprise - would naturally draw the diagram shown in Figure 1.

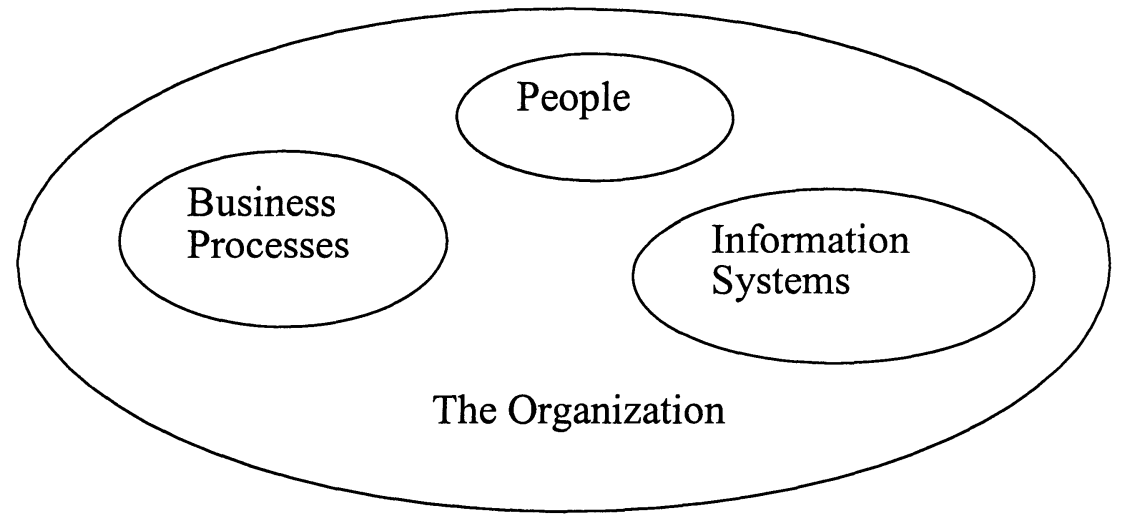

Figure 1. Managerial view of an information system (Silver et al 1995)

Silver et al. (1995) explain Figure 1 as follows: "Here, the organisation or enterprise is the supersystem, containing, among other things, people, business processes, and information systems." After looking Figure 1 we formed the conception that the organisation consists of business processes, people and information systems. After reading the explanation written by Silver et al. we wanted to ask two questions: 1 . Why did Silver et al. not use a fourth component such as 'other organisational activities' in Figure 1 when they use the phrase 'among other things' ? 2. Why is the outside of the organisation in Figure 1 not called an environment or explicitly 'other organisations'?

Our questions are based on Bunge's (1967 p.75) recommendation on good classification which is such that: a) the characters or properties chosen for 
performing the grouping should be consistent throughout the work; b) the subsets of the same hierarchical rank are exhaustive; c) and pair-wise disjoint; and d) the classification is natural. By following recommendation b) we get Figure 2 .

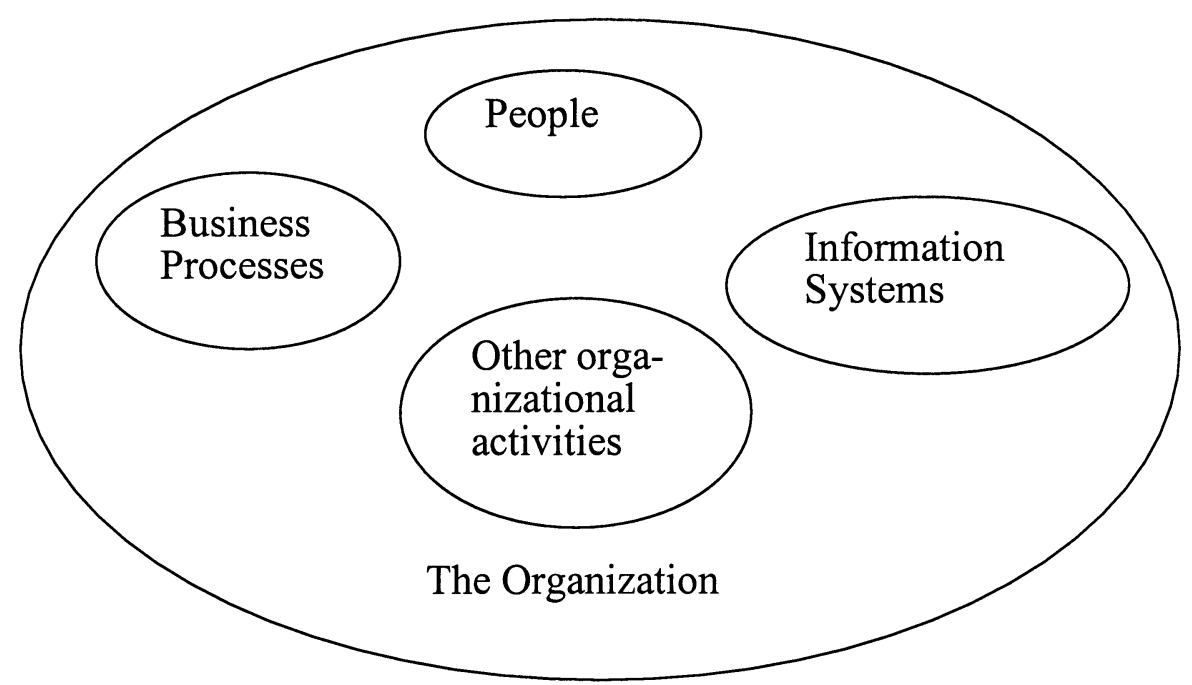

Figure 2. Managerial View of an Information System (our proposal)

Question 1 encourages us to demand the partitioning to be exhaustive (Bunge's point $b$ ). Also the other demands (Bunge's points a, c and d) are reasonable, and we have the lesson:

Lesson 1. Try to follow advice of the good classification (Bunge 1967 p.75) when you are partitioning a certain dimension into separate classes.

From our question 2 we derive the following lesson:

Lesson 2. Name the environment explicitly, when you draw the boundary of the system.

\section{CORRELATION}

Porter (1985 p.36) analysed every firm as a collection of activities that are performed to design, produce, market, deliver, and support its product. All these activities can be represented using a value chain, shown in Figure 3.

To our mind Figure 3 and its functions tell us that the production process proceeds from left to right. Figure 3 also resembles a two-dimensional table where every support activity is related to the primary activities but not to 
another support activity, i.e. it is unclear how the material, people and data resources needed in technology development are procured.

Porter himself explains his value chain as follows: "Every value activity employs purchased inputs, human resources (labour and management), and some form of technology to perform its function. Each value activity also uses and creates information, such as buyer data (order entry), performance parameters (testing), and product failure statistics. Value activities may also create financial assets such as inventory and accounts receivable, or liabilities such as accounts payable.

"Value activities can be divided into two broad types, primary activities and support activities. Primary activities, listed along the bottom of Figure 3, are the activities involved in the physical creation of the product and its sale and transfer to the buyer as well as after sale assistance. In any firm, primary activities can be divided into the five generic categories shown in Figure 3. Support activities support the primary activities and each other by proving purchased inputs, technology, human resources, and various firm-wide functions. Dotted lines reflect the fact that procurement, technology development, and human resource management can be associated with specific primary activities as well as support the entire chain."

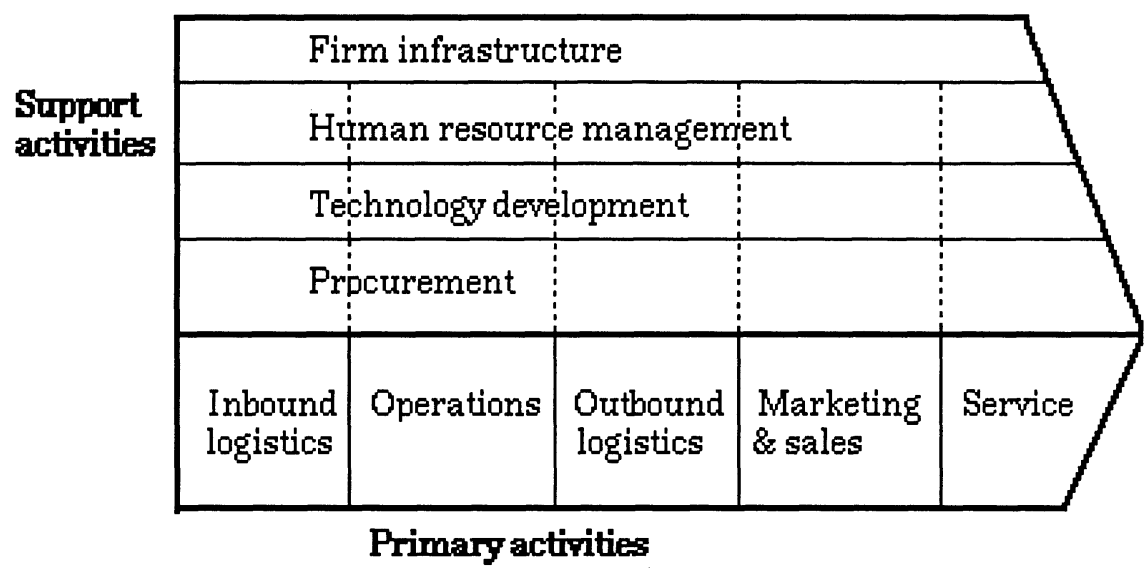

Figure 3. Porter's generic value chain

Porter has defined activities in his model (Porter 1985 pp.39-43). We do not here repeat all of them, but some few ones only.

Inbound logistics. Activities associated with receiving, storing and disseminating inputs to the product, such as material handling, warehousing, inventory control, vehicle scheduling and returns to suppliers.

Procurement. Procurement refers to the function of purchasing inputs used in the firm's value chain, not to the purchased inputs themselves. Purchased inputs include raw materials, supplies and other consumable items as well as assets such as machinery, laboratory equipment, office equipment and buildings. Though purchased inputs are commonly associated with primary 
activities, purchased inputs are present in every value activity including support activities.

Porter's definition of procurement is clearly in conflict with his pictorial presentation, because his verbal expression says that the procurement support activity serves primary activities and also other support activities. Hence, Figure 3 must be re-drawn. The boundaries between support activities must be deleted. In addition, we would like to analyse more deeply the support activities and build a new competing model for the value chain.

Porter and Millar (1985) concluded that information technology is permeating the value chain at every point, transforming the way value activities are performed and the nature of the linkages among them. The information revolution affects all the nine categories of value activity (Figure 3).

Referring to the special emphasis on information and financial resources we separate them from the class 'firm infrastructure' to become independent supporting functions. We also combine 'procurement' with 'inbound logistics' and leave some minor functions (if there are any) to the remainder class 'other supporting activities'. Thus we have not lost anything from Porter's model (Figure 3), but we have only grouped them in a new way. We have tried to follow Bunge's (1967 p.75) recommendation on good classification ( $a, b, c, d)$ mentioned in the former section. We have partitioned supporting functions according to various resource types and we have combined 'procurement' with 'primary activities', because it acquires raw material from which products proper are produced. Our new model of value chain is in Figure 4.

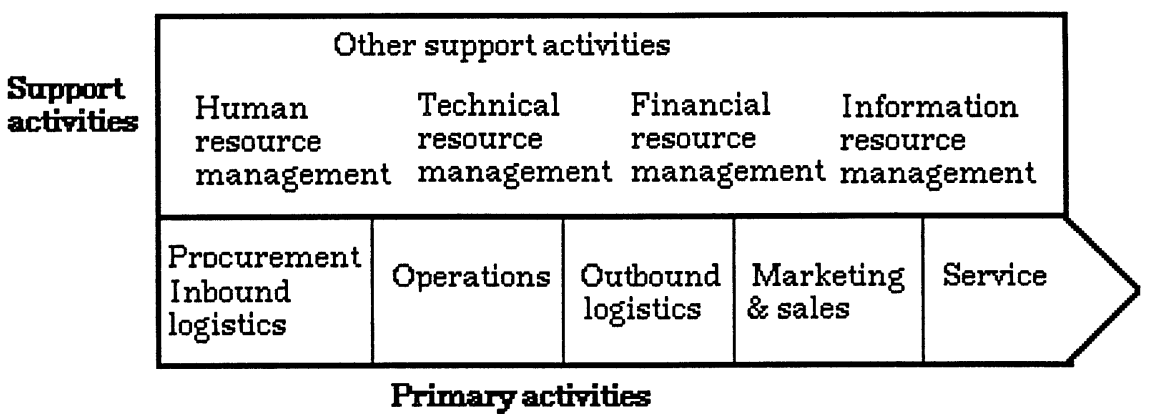

Figure 4. A new model of value chain (our proposal)

We can collect our lesson from this section as follows:

Lesson 3. Observe that the tabular form easily creates a view that there is a correlative relationship between those dimensions forming $x$ and y-axes. Try to avoid misconceptions by not drawing more classes into either dimension than necessary. 
We have understood that Porter's value chain can be applied only once. In practice, there are many times a need to apply the same model repeatedly, e.g. an idea of internal entrepreneurship has been introduced in certain firm. For example, the information systems department can be considered as a profit centre (Figure 5).

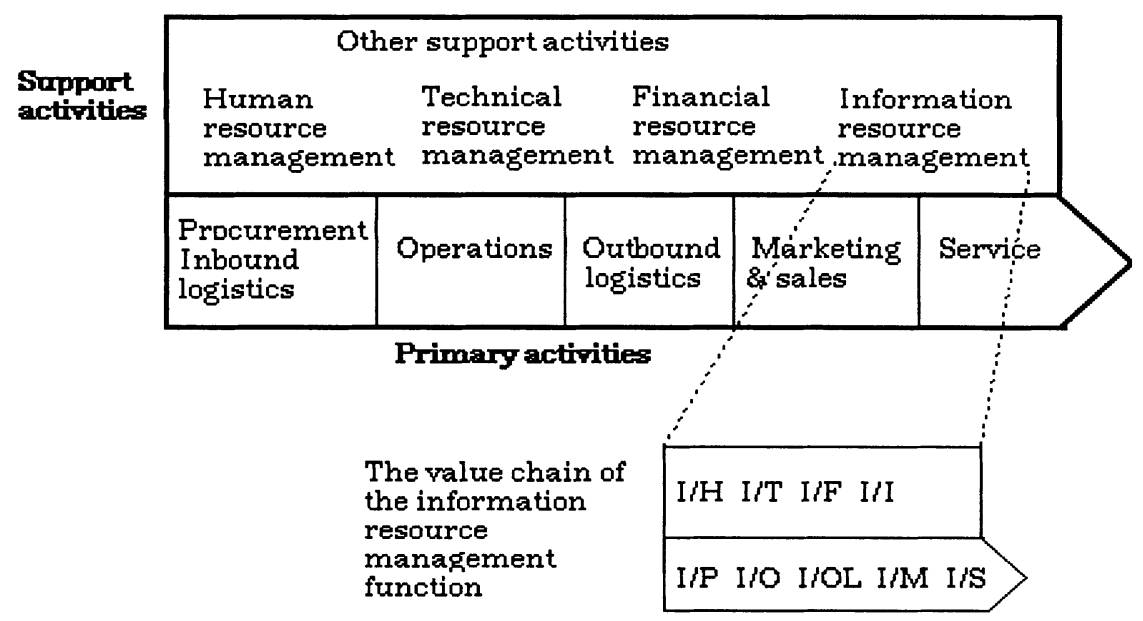

Figure 5. The information systems department as a profit centre

The other reason for the recursive application of the new value chain (Figure 5) is that if a firm is kept as a system, its functions can then be kept as subsystems.

Lesson 4. Test the possibility to recursively apply a model when a system has been modelled.

\section{NESTING}

Our first example concerned the component relationship between elements of the construct, the second concerned potential correlation. Next we consider an inclusive relationship. Daft (1978) proposed a dual-core model of organisational innovation with administrative and technical innovations. Swanson (1994) defined information systems (IS) innovation as innovation in the organisational application of digital computer and communications technologies (IT). Swanson also extended Daft's (1978) dual core model to incorporate a third functional IS core, serving to link the other two cores, administrative and technical, together. Swanson (1994) wrote: "As will become apparent, this serves to illuminate IS innovation among organisations, in terms of business impact, where the current dual-core model mostly masks it. The resulting tri-core model of IS innovation may be portrayed (for easy to recall)" as in Figure 6. 


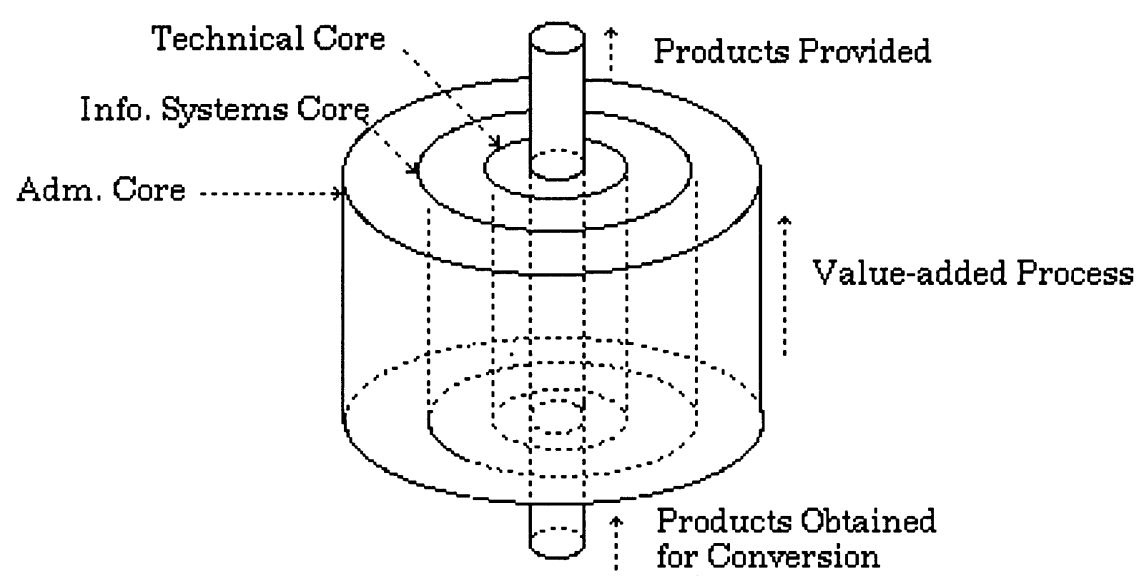

Figure 6. The domain of IS innovation in organisations: a tri-core representation

In the footnote of his article Swanson (1994) wrote, " We use the term 'model' very loosely here to refer our reasoning about differentiation of the cores". Figure 6 is intended only as an iconographic summary.

Despite Swanson 's many reservations, we cannot deny that based on Figure 6 we understand the technical core to be the innermost cylinder surrounded by the information systems core, and the latter is surrounded by the administrative core, i.e. three surfaces of the nested cylinders. Grover et al. (1997) tested the Swanson's tri-core model of IS innovation and in their cylinder figure the innermost cylinder corresponds to the administrative core and the outmost cylinder to the technical core. To our mind either a slip of pen happened to Grover et al. or they re-interpreted the tri-core model. The latter possibility also shows a problematic role of the construct, especially in its nested nature.

We could perform a thought experiment: Swanson separated the information systems from administrative function. What will happen if we also separate the human resource function from the administrative functions? Will it be located as the second innermost cylinder or the third or fourth one in Figure 6 ? To our mind there are no arguments for the nested order in any form.

Swanson's identified six types of IS innovations and they correspond to the three cores as follows: Type I innovations confined to the IS task (Ia admin.; Ib - tech.); Type II innovations supporting administration of the business; and Type III innovations imbedded in the core technology of the business (IIIa - process, IIIb - product, IIIc - integration).

In order to eliminate the 'cylinder' effect with its implicit connotations we locate those six types of IS innovations into our new model of value chain (Figure 7). 


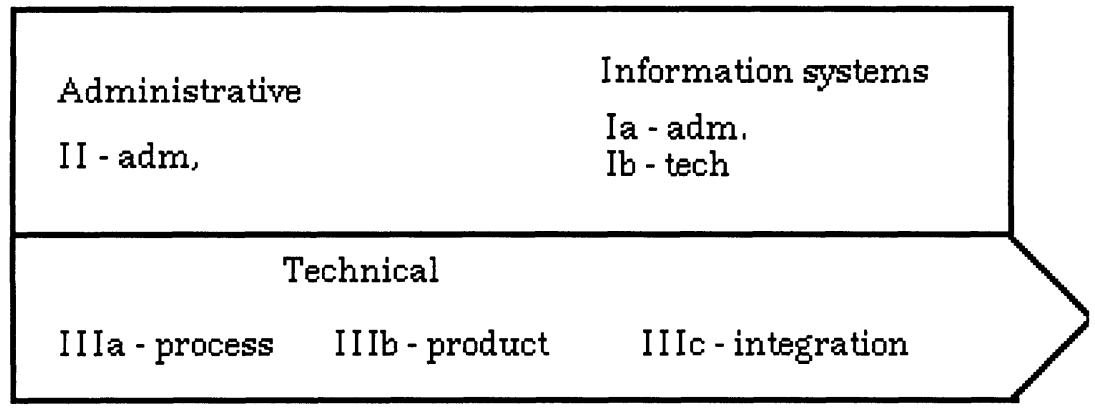

Figure 7. Swanson's six IS innovations in a value chain (our proposal)

In Figure 7 there are three components of the organisation. Three components of a certain whole are sometimes described as a triangle in a figure, although the whole may also contain other components not pictorially drawn. Based on ideas presented above we derive the following lessons:

Lesson 5. If the components of the model are not ordered, do not create any implicit ordering in a figured form of the model.

Lesson 6.If the number of components in the model are not exactly determined, do not use a couple, triangle, rectangle, pentagon etc. in a figure, although you recognise two, three, four, five, etc. components, respectively.

In lesson 6 we applied Bunge's recommendation for a good classification mentioned above. 


\section{EXPLICIT AND IMPLICIT FEATURES OF A DESCRIPTION LANGUAGE}

Lundeberg and his group in the late sixties already started to develop the ISAC methodology for information systems development (ISD). In the ISAC approach, information systems are specified on three levels: 1) change analysis; 2) activity studies; and 3) information analysis (Lundeberg 1982).

At the highest level, change analysis $(\mathrm{C})$ is divided into the following: $\mathrm{C} 1$ ) analysis of problems, current situation, and needs; C2) study of change alternatives; and C3) choice of change approach.

At the highest level, activity studies (A) in information systems development is divided into the following: A1) partitioning in information subsystems; A2) study of information subsystems; and A3) co-ordination of information subsystems.

The different steps during information analysis (I) are: I1) precedence and component analyses; I2) process analysis; and I3) property analysis. Precedence analysis involves the analysis of information precedence relations in an information system. Here the information sets that are needed in order to derive a certain information set are analysed. Component analysis involves the analysis of the structure on information sets.

Process analysis means making a detailed description of the information processes in the information system. During the precedence analysis processes are disregarded. The nodes of the I-graphs represent information precedence relations. Each process is described separately. The description is documented in process tables (decision tables) which consist of two parts: prerequisites and calculations. - The symbols used in I-graphs are presented in Figure 8. 


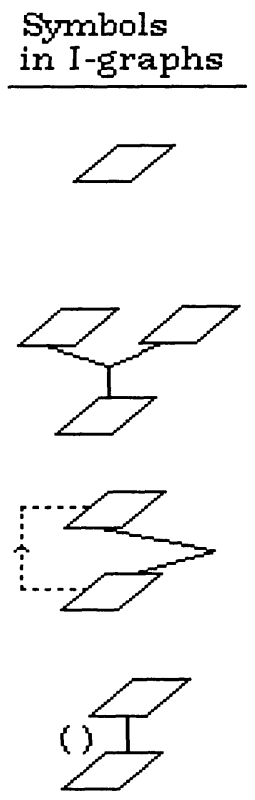

Correspondence in described information system

\section{Information set}

An information set consists of a number of messages, an information set is described by the information content in these messages

Precedence relation

Relation between information sets, the precedence relation is illustrated by a node and number of branches

Permanent information set An information set which exists in different generations, i.e. with a similar structure but with information content from different points of time

Fictitious precedence relation Two identical information sets are shown by a fictitious precedence relation, indicated by the parentheses without a reference code

Figure 8. Symbols used in I-graphs (Lundeberg 1982, 208)

The symbols in Figure 8 represent units that can be used in representations where an artificial language, the I-graph language is used. We shall investigate in the following study what can be expressed by using the Igraph language.

We have taken Figure 9 as an example of I-graphs from Lundeberg's (1982 p.212) article. It concerns an application for organising a scientific conference, and in that context for taking care of a file of (potential) attendees. 


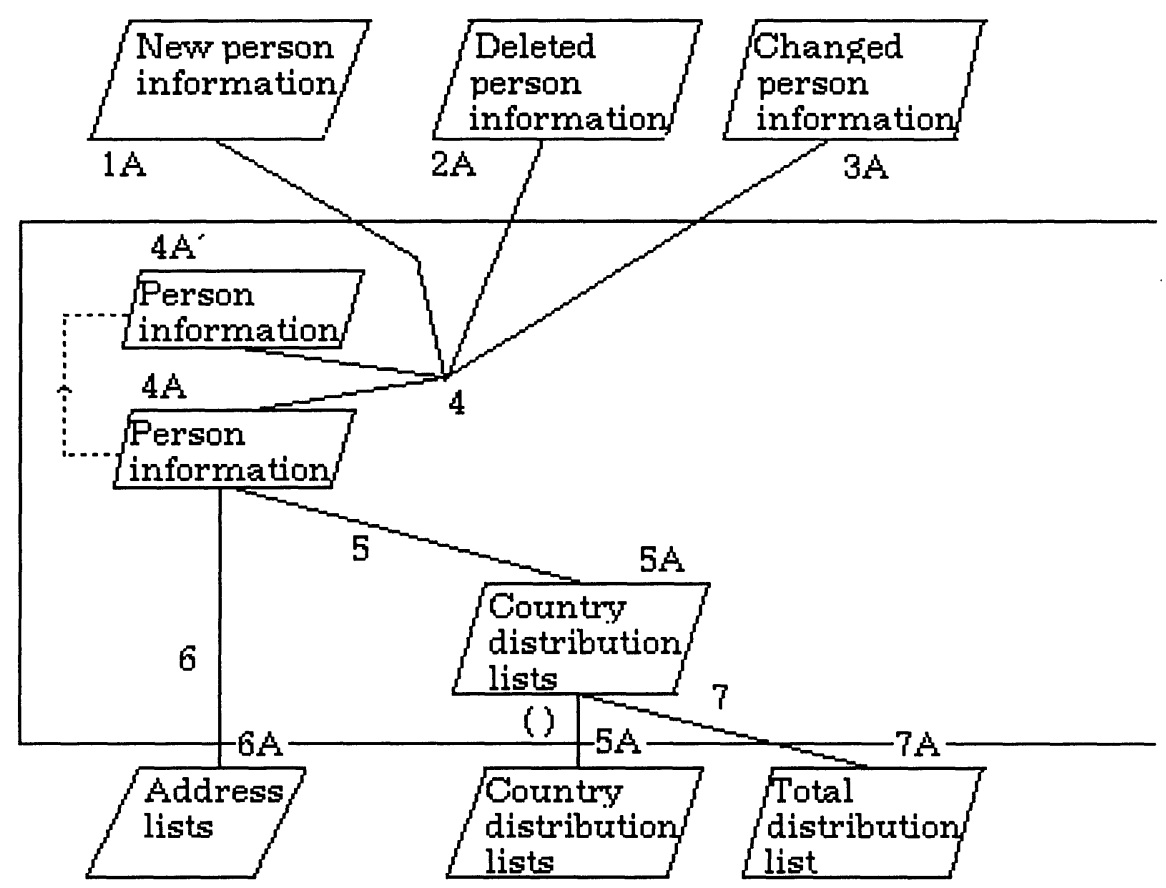

Figure 9. Processes to produce distribution lists

From our point of view, data processing in Figure 9 seems to straightforwardly proceed from top to bottom, i.e. from input to output. Process 4 contains a loop and means updating the file of person information. We cannot see whether or not a conference organiser can interactively feed transactions to the updating program.

Before deriving any recommendation we consider two comments from the literature. Tyllilä $(1980 \mathrm{a}, 1980 \mathrm{~b})$ found that with respect to the ways to describe information flows through the system the I graphs are close to traditional flowcharts. He continues "there are processes in Lundeberg's diagrams (flowcharts) and a coupling of them gives some intuitions from the control structure. This description technique is not suitable, if the control structure involves conditions, parallelisms or possibilities to perform tasks in different order. It describes these properties of control partially and only partially and that causes some implicit constructive ideas from the inner structure of the system. Lundeberg's diagrams are in this interpretation open to Parnas' (1972) criticism.

In their feature analysis of some ISD methodologies, Iivari and Kerola (1983) posed many questions. They, for example, asked: Q12. Does the concept structure cover the interaction between the data system and its users? 
Concerning the ISAC methodology they came into the conclusion: "Manmachine dialogue is mentioned in Lundeberg et al. (1981 p.301) but there is no clear mechanism for the specification of the interaction". Lundeberg (1983) in his comment emphasised the relevance as one of the main goals of the ISAC. He also confirmed Iivari's and Kerola's finding by writing "the purpose of information analysis in the ISAC is to document a user oriented specification of the information needs. ... If we turn to information analysis of NIAM, the purpose of the conceptual schema is to 'completely and exclusively prescribe all the permitted states and all the permitted transition of the data base' (Falkenberg et al. 1983). In my (Lundeberg's) conclusion is that information analyses in the ISAC and in the NIAM are almost complementary methods." This means that Lundeberg himself admits that a systems analyst cannot manage a human-computer interaction with notations developed (Figure 8) for information analysis in the ISAC.

To give an other way to express functions in Figure 9 we developed Figure 10 .

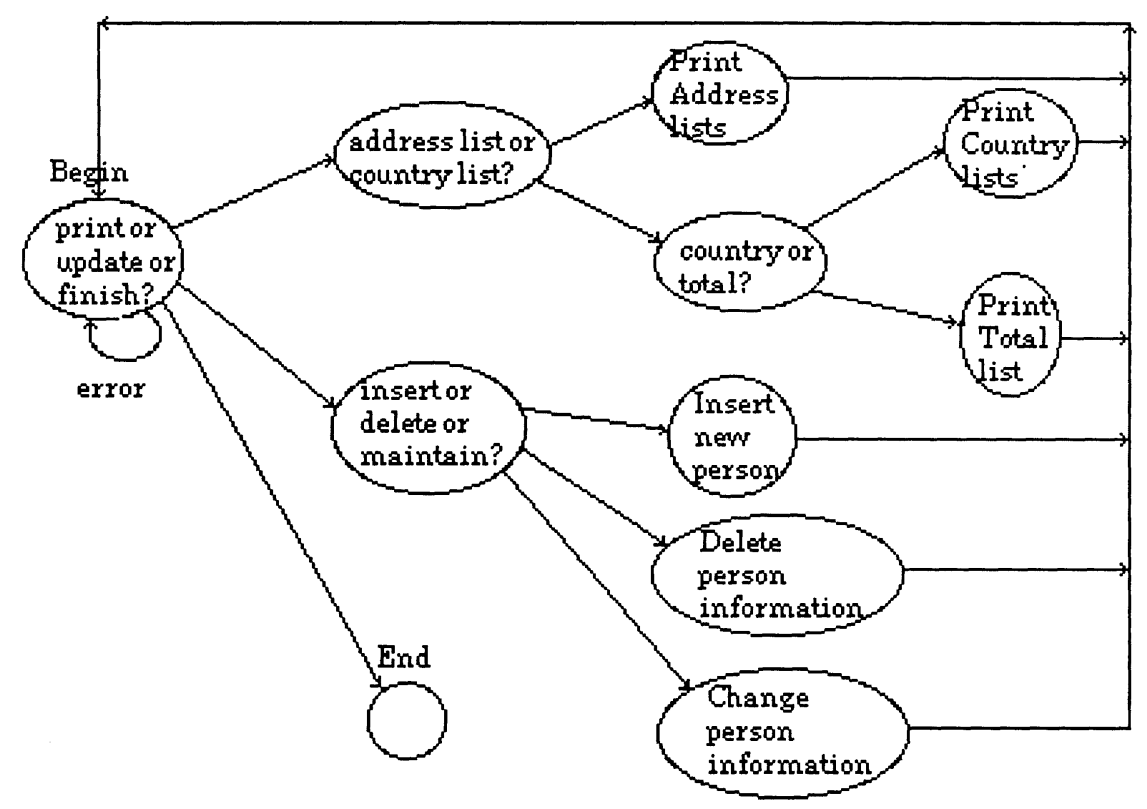

Figure 10. Processes to produce distribution lists (our proposal)

In Figure 10 we partly used the transition network model (Green 1986). The larger system moves control to this component in the 'Begin' node and this component moves control back to the larger system in the 'End' node. In Figure 10 there are no backtracking, i.e. if a user changes his/her mind and wishes to cancel the latest selection, those arrows are left out for simplicity. In the 'Begin' node there is the 'error' arrow describing that a user selected 
some fourth function instead of 'printing', 'updating' and 'finishing'. The similar 'error' arrows must be connected to every node, but they are excluded for simplicity. If a user selects 'printing' in the 'Begin' node, s/he can then select either 'address list' or 'country list', and for the latter still 'country list' or 'total list'. After printing some of those lists, control returns to the node 'Begin' and a user can select either 'printing', 'updating' or 'finishing'. In the 'updating' case a user can then select either 'inserting', 'deleting' or 'maintaining', and then either 'add new person information', 'delete person information' or 'change person information', respectively. After performing some updating, control again returns to the node 'Begin'. Hence, our Figure 10 seems to contain the same functionality as Figure 9. We can say that by using the transition network model we succeeded in describing interaction and iteration, whereas the actions were difficult or impossible to describe with the I-graph primitives.

We conclude that notations for I-graphs seem to unconsciously lead systems analysts to build batch processing systems, because there are inputs at the top, outputs at the bottom and processes to produce output from the input inside of the big rectangle, and no mechanism to describe interaction. From this we derive the following lessons:

Lesson 7. Be sure that the artificial language you use in describing features of a system is capable of presenting all the needed features of the model.

Lesson 8. Do not use such symbols and conventions in preparing figures that may implicitly lead to unexpected or unanticipated results.

\section{DISCUSSION}

In this section we firstly present our advice how to draw figures by repeating the lessons we derived. We then refer to Bunge (1973) and locate figures in the proper context with respect to theories.

To our mind, figures can considerably help in getting an overview of a particular thing to be learned. Our aim has been to build as realistic a view as possible. We therefore analysed some figures presented in the literature and found their drawbacks. In most cases we tried to present both our findings as lessons and some potential alternative where the similar drawback does not exist. Our lessons repeated below are presented in a rather general and abstract way and they are in that sense applicable to many other situations than those where they were found.

1. Try to follow advice of the good classification (Bunge 1967 p.75) when you are partitioning a certain dimension into separate classes.

2. Name the environment explicitly, when you draw the boundary of the system. 
3. Observe that the tabular form easily creates a view that there is a correlative relationship between dimensions forming $x$ - and $y$-axes. Try to avoid misconceptions by not drawing more classes into either dimension than necessary.

4. Test the possibility to recursively apply a model when a system has been modelled.

5. If the components of the model are not ordered, do not create any implicit ordering in a figured form of the model.

6. If the number of components in the model are not exactly determined, do not use a couple, triangle, rectangle, pentagon etc. in a figure, although you recognise two, three, four, five, etc. respectively components.

7. Be sure that the artificial language you use in describing features of a system is capable of presenting all the needed features of the model.

8. Do not use such symbols and conventions in preparing figures that may implicitly lead to unexpected or unanticipated results.

We want also to note that our set of lessons is not, however, exhaustive and more research is needed. Two directions can be immediately seen: 1) try to find some inner structure of the 8 lessons; and 2) try to find new important advice. In the course of preparing this paper we have found that almost all our examples describe some kind of relationships, as component, correlative, recursive, order and precedence relations. This finding may guide the further research work.

To locate figures in a proper context we refer to Bunge (1973 p.100) who writes that pictorial diagrams are not part and parcel of factual theoretical science although they may illustrate some parts of a theory in equivocal ways. They are not for the simple reason that a theory is, by definition, a set of statements not a mixture of statements and pictures. Pictures and, in general, metaphors may occur in the process of building, learning, teaching or applying a theory but they are not part of the theory.

\section{REFERENCES}

Bunge M. (1967) Scientific research I. The search for system. Springer-Verlag, Berlin.

Bunge M. (1973) Method, model and matter. D. Reidel Publ. Company, Dordrect.

Daft R.L. (1978) A dual-core model of organizational innovation. Academy of Management Journal 21(2) 193-210.

Falkenberg E., G.M. Nijssen, A. Adams, L. Bradley, P. Bugeia, A.L. Campell, M. Carkeet, G. Lehmann and A. Shoesmith (1983) Feature analysis of ADM/PCM, CIAM, ISAC and NIAM. In Olle, Sol and Tully (eds.) Information systems design methodologies: a feature analysis. Elsevier, Amsterdam, 169-189.

Foley J.D. and A. van Dam (1982) Fundamentals of interactive computer graphics. AddisonWesley, Reading Mass. 
Green M. (1986) A survey of three dialogue models. ACM Transaction on Graphics 5(3) 244-275.

Grover V., K. Fiedler and J. Teng (1997) Empirical evidence on Swanson's tri-core model of information systems innovation. Information Systems Research 8(3) 273287.

Iivari J. and P. Kerola (1983) A sociocybernetic framework for the feature analysis of information systems design methodologies. In Olle, Sol and Tully (eds.) Information systems design methodologies: a feature analysis. Elsevier, Amsterdam, 87-139.

Jarvenpaa S.L. and G.W. Dickson (1988) Graphics and managerial decision making: research based guidelines. Comm. ACM 31(6) 764-774.

Kosslyn S.M. (1994) Elements of graph design. W.H. Freeman and Company, New York.

Lundeberg M. (1982) The ISAC approach to specification of information systems and its application to the organization of an IFIP working conference. In Olle, Sol and Verrijn-Stuart (eds.) Information systems design methodologies: a comparative review. North-Holland, Amsterdam, 173-234.

Lundeberg M. (1983) Some comments on the ISAC approach in connection with CRIS-2 papers. In Olle, Sol and Tully (eds.) Information systems design methodologies: a feature analysis. Elsevier, Amsterdam, 251-257.

Lundeberg M, G. Goldkuhl and A. Nilsson (1981) Information systems development: $a$ systematic approach. Prentice-Hall, Englewood Cliffs.

Parnas D.L. (1972) On the criteria to be used in decomposing systems into modules. Comm. $A C M$ 15(12) 1053-1058.

Porter M.E. (1985) Competitive advantage - creating and sustaining superior performance. Free Press, New York.

Porter M.E. and V.E. Millar (1985) How information gives you competitive advantage. Harvard Business Review 63(3) 149-160.

Salmelin R. (1997) Graphical representation of statistical results in medical research. Acta Universitatis Tamperensis 551, University of Tampere, Finland.

Silver M.S., M.L. Markus, and C.M. Beath (1995) The information technology interaction model: a foundation for the MBA core course. MIS Quarterly 19(3), 361-390.

Strauss A. and J. Corbin (1990) Basics of qualitative research - grounded theory procedures and techniques. Sage Publications, Newbury Park Ca.

Swanson E.B. (1994) Information systems innovation among organizations. Management Science 40(9) 1069-1092.

Tufte E.R. (1983) The visual display of quantitative information. Graphics Press, Cheshire.

Tyllilä P. (1980a) Notes on why, what and how paradigm of systemeering: an example, conceptual independence of S-systemeering in PSC-systemeering model. In Lyytinen and Peltola (eds.) Report of the third Scandinavian research seminar on systemeering models. Institute of Computer Science, University of Jyväskylä, 126-131.

Tyllilä P. (1980b) Discussion and author's comment. In Lyytinen and Peltola (eds.) Report of the third Scandinavian research seminar on systemeering models. Institute of Computer Science, University of Jyväskylä, 132-139. 